\title{
AVALIAÇÃO DA QUALIDADE DE SEMENTES E MUDAS DE CEDRO
}

\section{QUALITY EVALUATION OF Cedrela fissilis SEEDS AND SEEDLINGS}

\author{
Edicléia Aparecida Iensen Cherobini ${ }^{2}$ Marlove Fátima Brião Muniz ${ }^{3}$ Elena Blume ${ }^{3}$

\section{RESUMO}

Pertencente à família Meliaceae, o cedro (Cedrela fissilis Vell) apresenta grande importância econômica e ecológica. A madeira é leve e fácil de trabalhar, sendo recomendada para a fabricação de móveis em geral e também é utilizada em paisagismo de parques e recomposição de áreas degradadas. $\mathrm{O}$ objetivo deste trabalho foi avaliar a qualidade de sementes de cedro coletadas nos estados do Rio Grande do Sul, Santa Catarina e Paraná por meio da realização de diversos testes de vigor, teste de sanidade e avaliar a qualidade das mudas produzidas partindo dessas sementes mediante testes em viveiro. O presente estudo mostrou que a presença de fungos, como Aspergillus spp. e Penicillium spp., pode causar perdas na germinação em conseqüência do apodrecimento de sementes. Pelos testes realizados com as sementes coletadas nos diferentes estados foi possível verificar que existem diferenças dos níveis de vigor entre as procedências. Os patógenos encontrados podem causar prejuízos á produção de mudas por causa do apodrecimento de sementes.

Palavras-chave: Cedrela fissilis; germinação; viabilidade; sanidade.

\section{ABSTRACT}

Belonging to the Meliaceae family, cedro (Cedrela fissilis Vell.) presents a great economical and ecological importance. The wood is light and easy to work, being suggested to the manufacturing of furniture in general, also it is used to reset degraded areas. The objective of this work was to evaluate the quality of Cedrela fissilis seedlings and seeds from Rio Grande do Sul, Santa Catarina and Paraná, through the accomplishment of varied tests of vigor, test of health and evaluation of the quality of seedlings produced from these seeds. The present study showed that the presence of fungi pathological potential - Aspergillus spp. and Penicillium spp. - can cause losses in the germination. Considering tests with seeds collected in the different states of the South Region, it was possible to verify that differences of the vigor levels exist. The fungi found in the seeds can cause damages in the production.

Keywords: Cedrela fissilis; germination; viability; sanity.

\section{INTRODUÇÃO}

O Cedro (Cedrela fissilis Vell.) é uma árvore caducifólia da família das Meliáceas, apresenta de 10 a $25 \mathrm{~m}$ de altura e 40 a $80 \mathrm{~cm}$ de DAP, podendo atingir até 40 metros de altura e $200 \mathrm{~cm}$ de DAP. (REITZ et al., 1988). É uma espécie que tem preferência por solos úmidos e profundos, mas possui capacidade de adaptação a diferentes ambientes. Trata-se de uma espécie secundária inicial à secundária tardia, que se desenvolve no interior da floresta primária, mas que apresenta grande agressividade na vegetação secundária, constituída de capoeirões e floresta secundária. A freqüência do cedro nas florestas do sul do Brasil varia de uma a três árvores por hectare (LORENZI, 1992).

Como planta ornamental, o cedro é uma espécie recomendada para arborização de praças públicas, sendo muito empregada em obras de paisagismo. Também é recomendada para recuperação de áreas degradadas e para reposição de matas ciliares em locais com ausência de inundação, pois o crescimento é rápido, exceto em locais sujeitos a geadas (SANTOS et al., 2001).

Na produção de mudas, por sementes, os frutos devem ser coletados maduros diretamente da árvore, porém ainda fechados para evitar a perda de sementes, e, após a coleta, levados para completar a deiscência em ambiente seco e ventilado (LORENZI, 1992). A avaliação da qualidade de sementes é de grande

1. Parte do trabalho de dissertação de Mestrado do primeiro autor.

2. Engenheira Florestal, MSc., Programa de Pós-Graudação em Engenharia Florestal, Centro de Ciências Rurais, Universidade Federal de Santa Maria, Av. Roraima, 1000, CEP 97105-900, Santa Maria (RS). edicherobini@yahoo.com.br

3. Engenheira Agrônoma, Dr $^{\mathrm{a}}$, Professora do Departamento de Defesa Fitossanitária, Centro de Ciências Rurais, Universidade Federal de Santa Maria, Av. Roraima, 1000, CEP 97119-900, Santa Maria (RS). marlove@smail.ufsm.br/eblume@smail.ufsm.br

Recebido para publicação em 20/07/2006 e aceito em 6/12/2007. 
importância para o armazenamento e produção de mudas.

O vigor é um dos aspectos mais importantes na análise da qualidade de sementes, considerando que o processo de deterioração está diretamente relacionado com a perda do vigor. Marcos Filho (1994) descreve que o vigor das sementes é reflexo de um conjunto de características ou propriedades que determinam o seu potencial fisiológico, ou seja, o comportamento quando são expostas às diferentes condições ambientais. Figliolia et al. (1993) relatou que a análise de sementes é de fundamental importância na medida em que fornece parâmetros que expressam as qualidades física e fisiológica do lote de sementes, para fins de semeadura e armazenamento.

A presença de patógenos após o ponto de maturidade fisiológica ou armazenamento das sementes é ameaça séria á qualidade devido ao fato que elevadas percentagens de sementes infeccionadas estão associadas. (YORINORI, 1982).

Entre as espécies florestais nativas, poucos estudos têm sido feitos sobre a transmissão de fungos por sementes. As sementes são atacadas por patógenos, tanto no campo quanto nas operações subseqüentes de colheita, secagem e beneficiamento (CARNEIRO, 1990).

Fungos com potencial fitopatogênico pertencentes a diferentes gêneros, como Fusarium spp., Alternaria spp., Cylindrocladium spp., entre outros, têm sido encontrados associados às sementes de espécies florestais podendo causar necrose no sistema radicular, lesões no colo das mudas, tombamento, murcha e morte de plântulas, diminuição no poder de germinação e podridão de sementes. (CARNEIRO, 1986).

Este trabalho teve como objetivo avaliar a qualidade de sementes de cedro coletadas no Rio Grande do Sul, Santa Catarina e Paraná e das mudas produzidas por essas sementes.

\section{MATERIAIS E MÉTODOS}

O trabalho foi conduzido nas instalações do Laboratório de Fitopatologia do Departamento de Defesa Fitossanitária do Centro de Ciências Rurais, Laboratório de Ecologia Florestal, Laboratório de Sementes e Casa de Vegetação do Departamento de Ciências Florestais, do Centro de Ciências Rurais da Universidade Federal de Santa Maria.

As sementes utilizadas procederam de três microrregiões representando os Estados e respectivos municípios de coleta: Rio Grande do Sul - Santa Cruz do Sul; Santa Catarina - Rio do Sul; e Paraná - Iratí e foram coletadas de maio a junho de 2004.

\section{Avaliação das Sementes}

Antes do início dos testes, foi determinado o grau de umidade das sementes pelo método da estufa (estufa de secagem, marca De Leo, modelo 400/4ND200), realizado com quatro subamostras, sob a temperatura de $105 \pm 3^{\circ} \mathrm{C}$, por 24 horas, e os resultados foram expressos em percentagem (BRASIL, 1992). Quatro repetições com cinqüenta sementes foram submetidas às seguintes determinações de vigor: a) Teste de germinação, as sementes foram colocadas para germinar em caixas do tipo gerbox, sobre três folhas de papel filtro umedecido com água destilada na proporção de duas vezes o peso do papel seco, sendo utilizadas quatro repetições, com cinqüenta sementes (PIVETTA et al., 2001). Utilizou-se um germinador marca Quimis, modelo Q-315T, com temperatura constante de $25^{\circ} \mathrm{C}$, com 8 horas de luz e 16 horas de escuro As contagens foram realizadas aos 7 e 14 dias; b) Indice de velocidade de germinação, conduzido de acordo com Popiginis (1977), em conjunto com o teste de germinação, com contagens diárias do número de plântulas germinadas. Para cada repetição, foi calculado o índice de velocidade de germinação (IVG), somando-se o número de sementes germinadas a cada dia, divididas pelo respectivo número de dias transcorridos partindo da semeadura; c) Primeira contagem, conduzido juntamente com o teste de germinação, na primeira contagem serão retiradas as plântulas normais, ou seja, aquelas que germinaram mais rapidamente. As amostras que apresentaram maior porcentagem de plântulas normais são as mais vigorosas. Os equipamentos e materiais utilizados foram os mesmos necessários para o teste de germinação; d) Comprimento de plântulas, avaliado pela medição do comprimento das plântulas normais na primeira e na segunda contagem do teste de germinação, com auxílio de régua milimetrada, o comprimento médio das plântulas foi obtido somando-se as medidas de cada repetição e dividindo-se pelo número de plântulas normais, com resultados expressos em cm (KRZYZNOWSKI et al., 1999); e) Massa da 
matéria fresca de plântulas, as plântulas foram divididas em quatro repetições e pesadas em balança com precisão de $0,001 \mathrm{~g}$, marca Bioprecisa, modelo JH2102, e o valor obtido pela soma de cada repetição foi dividido pelo número de plântulas utilizadas. Os resultados foram expressos em $\mathrm{mg} / \mathrm{plântula;} \mathrm{f)} \mathrm{Massa} \mathrm{da}$ matéria seca; as plântulas foram mantidas em sacos de papel divididas em quatro repetições e colocadas em estufa a $80^{\circ} \mathrm{C}$ por 24 horas. Após, foram pesadas em balança com precisão de $0,001 \mathrm{~g}$ e o valor obtido pela soma de cada repetição foi dividido pelo número de plântulas utilizadas. Os resultados foram expressos em mg/plântula (KRZYZANOWSKI et al., 1999); g) Envelhecimento acelerado, utilizado o método da câmara de envelhecimento, (KRZYZANOWSKI et al, 1999.). A temperatura utilizada foi de $42^{\circ} \mathrm{C} \pm 2{ }^{\circ} \mathrm{C}$, utilizaramse quatro repetições com cinqüenta sementes e após decorrido o período de 48 horas, as sementes foram colocadas para germinar utilizando-se a temperatura de $25^{\circ} \mathrm{C}$, com 8 horas de luz; h) Condutividade elétrica, realizado com cem sementes divididas em quatro repetições e pesadas em balança de $0,001 \mathrm{~g}$. Em seguida, as sementes foram colocadas em caixas gerbox, contendo $75 \mathrm{ml}$ água deionizada e mantidas por 24 horas em câmara a $25^{\circ} \mathrm{C}$. Foi utilizado um condutivímetro marca Eletrolab, modelo CP600 Plus. (VIEIRA e KRYZYANOWSKI, 1999); i) Teste de sanidade, realizado por meio do método "Blotter test", em amostras de duzentos sementes, divididas em oito subamostras, colocadas em caixas de plástico tipo "gerbox", sobre três folhas de papel filtro esterilizadas e umedecidas com água destilada e esterilizada. A incubação foi realizada em estufa, marca Eletrolab, modelo $121 \mathrm{FC}$, à temperatura aproximada de $25^{\circ} \mathrm{C}$, durante o período 12 horas de iluminação com lâmpadas fluorescentes, alternadas com 12 horas de escuro, durante 7 dias. Após este período, foram avaliados os microrganismos presentes nas sementes, pela observação das estruturas em microscópios ótico e estereoscópio (BARNET e HUNTER, 1972).

\section{Avaliação das Mudas}

O experimento foi realizado em casa de vegetação climatizada, localizada no Viveiro Florestal do Departamento de Ciências Florestais da UFSM. A avaliação da qualidade das mudas foi realizada partindo da semeadura, em recipientes individuais (tubetes), e, que foram colocadas duas sementes por recipiente, utilizando-se cem tubetes e duzentas sementes, os recipientes foram preenchidos com substrato comercial Plant Max. Foram realizadas as seguintes avaliações:

a) Emergência - realizou-se a contagem de plantas presentes por amostra 30 dias após a semeadura.

b) Mudas aptas para transplante - Após 45 dias da semeadura, as mudas foram avaliadas, considerando-se: (1) Sanidade - as mudas que apresentaram sintomas de doenças, como morte de mudas em reboleiras, lesões de tecido na região do colo, murcha e seca. (2) Número final de plantas, a germinação foi avaliada pela percentagem de mudas que permaneceram até o final do experimento aos 45 dias. (3) Comprimento de mudas, a medição da altura total de mudas foi realizada com o auxílio de uma régua milimetrada, e os valores foram expressos em centímetros. (4) Diâmetro do colo de mudas, o diâmetro do colo foi medido usando-se um paquímetro digital.

c) Massa fresca e massa seca de mudas - para determinação do peso fresco, as mudas foram acondicionadas em sacos de papel, divididas em quatro repetições e pesadas, sendo logo após colocadas em estufa a $80^{\circ} \mathrm{C}$ por 24 horas, sendo posteriormente, pesadas em balança com precisão de $0,001 \mathrm{~g}$ e, então, determinado o peso da matéria seca total das mudas. Os resultados foram expressos em gramas. Assim, para este teste, as amostras que apresentaram maiores pesos médios de matéria seca de plântulas normais foram consideradas mais vigorosas.

Delineamento experimental, foi o completamente casualizado, com quatro repetições. Os dados obtidos nos testes de germinação, primeira contagem, envelhecimento acelerado e teste de tetrazólio foram transformados em arc sen. $\sqrt{ } \mathrm{x} / 100$ e submetidos à análise de variância. A comparação de médias entre as diferentes procedências das sementes foi realizada pelo do teste de Tukey a $5 \%$ de significância. Foram realizados testes de correlações simples entre as diferentes variáveis (ZONTA e MACHADO, 1984).

\section{RESULTADOS E DISCUSSÃO}

Os resultados do teor de umidade e do teste de germinação para Cedrela fissilis encontram-se na Tabela 1. Verifica-se que não houve diferença significativa no teor de umidade entre os lotes de sementes dos diferentes locais. A uniformização do grau de umidade das sementes é importante para a execução dos testes, para a padronização das avaliações e para a obtenção de resultados consistentes (MARCOS FILHO et 
al., 1987).

Verifica-se que ocorrem diferenças significativas para o teste de germinação, separando as sementes em dois lotes por procedência. As sementes coletadas no Rio Grande do Sul apresentaram maior percentagem de germinação (89\%), mas não diferenciaram das sementes coletadas em Santa Catarina (79\%). Esses dois locais diferenciaram do Paraná que teve germinação de (36\%) e também apresentou a maior percentagem de sementes mortas (38\%). A percentagem de sementes dormentes foi menor para a procedência do RS (6,0\%), já as sementes coletadas em SC e PR não diferenciaram estatisticamente.

TABELA 1: Avaliação de sementes de Cedrela fissilis, coletadas no Rio Grande do Sul, Santa Catarina e Paraná.

TABLE 1: Evaluation of Cedrela fissilis seeds, collected in Rio Grande do Sul, Santa Catarina and Paraná.

\begin{tabular}{c|c|c|c|c}
\hline \multicolumn{5}{c}{ Variáveis analisadas (\%) } \\
\hline Local & TU & G & SD & SM \\
\hline RS & $15,7 \mathrm{a}$ & $89,0 \mathrm{a}$ & $6,0 \mathrm{~b}$ & $5,0 \mathrm{~b}$ \\
SC & $15,5 \mathrm{a}$ & $79,0 \mathrm{a}$ & $15,0 \mathrm{a}$ & $6,0 \mathrm{~b}$ \\
PR & $16,0 \mathrm{a}$ & $36,0 \mathrm{~b}$ & $26,0 \mathrm{a}$ & $38,0 \mathrm{a}$ \\
\hline CV (\%) & 0,46 & 1,95 & 1,46 & 2,51 \\
\hline D.M.S & 0,09 & 0,49 & 0,31 & 0,54
\end{tabular}

Em que: Médias seguidas pela mesma letra, na coluna, não diferem entre si pelo teste de Tukey, a 5\%; TU = teor de umidade; $\mathrm{G}=$ germinação; $\mathrm{SD}=$ sementes dormentes; $\mathrm{SM}=$ sementes mortas.

De acordo com estudos de Marcos Filho et al. (1987), é importante a comparação de lotes de sementes com germinação semelhante, pois os testes de vigor podem mostrar diferenças não-observadas no teste de germinação. Pivetta et al. (2001), estudando a germinação de sementes de C. fissilis sob diferentes condições de temperatura e luz, observaram que as sementes de cedro germinam bem, tanto na presença como na ausência de luz, sendo que a ausência de luz proporciona maior germinação. No presente trabalho, sob as mesmas condições de execução do teste de germinação, a resposta das sementes foi diferente, dependendo do local de coleta.

O teste de germinação é o mais utilizado para avaliar a qualidade fisiológica de sementes de diferentes espécies, porém, ele é realizado em condições favoráveis e ótimas para a espécie, não refletindo o comportamento destas no campo, assim como não detectando estágios avançados de deterioração (FRANÇA NETTO et al., 1986).

Os testes de vigor realizados em laboratório para avaliar a qualidade dos lotes das sementes de Cedrela fissilis e apresentados na Tabela 2, mostraram diferenças significativas entre os locais de coleta. $\mathrm{O}$ teste de primeira contagem de germinação, realizado no sétimo dia, mostrou-se sensível para demonstrar diferenças de vigor entre os locais de coleta das sementes, separando as sementes em dois grupos, sendo as do Rio Grande do Sul e Santa Catarina mais vigorosas do que as do Paraná. Essa separação em dois grupos pode ser observada também pelo índice de velocidade de germinação, no qual se observa um maior IVG para sementes coletadas no Rio Grande do Sul e um menor para sementes coletadas no Paraná. Conforme Nakagawa (1999), a medida que a deterioração das sementes aumenta, a velocidade de germinação é reduzida, sendo assim, os lotes que apresentarem maior percentagem de germinação na primeira contagem podem ser considerados mais vigorosos.

As sementes coletadas em Santa Catarina, apresentaram maior peso de matéria fresca e maior peso de matéria seca de plântulas, indicando maior vigor com relação às sementes dos lotes coletados no Rio Grande do Sul e Paraná, que não diferiram entre si. De acordo com Dan et al., (1987) as sementes vigorosas originam plântulas com maior taxa de crescimento, em função de apresentarem maior capacidade de transformações e suprimento de reservas de armazenamento e da maior incorporação destes pelo eixo embrionário.

Os resultados obtidos pelo teste de envelhecimento acelerado também indicaram as sementes do Rio Grande do Sul e Santa Catarina como as de maior vigor e a do Paraná como de menor vigor. Verificou-se que o período de 48 horas e temperatura de $42^{\circ} \mathrm{C}$, foram eficientes na separação dos lotes coletados nos diferentes estados. Cherobini et al (2005) obtiveram diferenciação dos lotes de Sesbania virgata Poir, 
quando submeteram as sementes a um período de 72 horas de envelhecimento acelerado, após esse período observaram redução na percentagem de germinação. Para Marcos Filho (1999), o teste de envelhecimento acelerado, que avalia o comportamento de sementes submetidas à temperatura e umidade relativa do ar elevadas, é considerado um dos mais sensíveis para a avaliação do vigor.

TABELA 2: Valores médios obtidos nos testes de vigor para avaliar sementes de Cedrela fissilis coletadas no Rio Grande do Sul, Santa Catarina e Paraná.

TABLE 2: Average values of the vigor tests to evaluate Cedrela fissilis seeds, collected in Rio Grande do Sul, Santa Catarina and Paraná.

\begin{tabular}{l|c|c|c|c|c|c|c}
\hline Locais & PC (\%) & IVG & CP $(\mathrm{cm})$ & PMF $(\mathrm{g})$ & PMS $(\mathrm{g})$ & EA (\%) & $\mathrm{CE}\left(\mu \mathrm{s} \mathrm{cm}^{-1} \mathrm{~g}^{-1}\right)$ \\
\hline RS & $73,0 \mathrm{a}$ & $1,7 \mathrm{a}$ & $6,8 \mathrm{~b}$ & $1,3 \mathrm{~b}$ & $0,15 \mathrm{~b}$ & $64,0 \mathrm{a}$ & $107,0 \mathrm{~b}$ \\
SC & $61,0 \mathrm{a}$ & $1,2 \mathrm{ab}$ & $8,9 \mathrm{a}$ & $3,3 \mathrm{a}$ & $0,33 \mathrm{a}$ & $62,0 \mathrm{a}$ & $104,0 \mathrm{~b}$ \\
PR & $21,0 \mathrm{~b}$ & $0,5 \mathrm{~b}$ & $8,8 \mathrm{a}$ & $0,63 \mathrm{c}$ & $0,17 \mathrm{~b}$ & $40,0 \mathrm{~b}$ & $168,0 \mathrm{a}$ \\
\hline CV (\%) & 3,4 & 40,0 & 12,9 & 19,4 & 4,1 & 3,4 & 9,4 \\
\hline D.M.S & 0,82 & 0,93 & 2,07 & 0,08 & 0,89 & 0,91 & 23,5 \\
\hline
\end{tabular}

Em que: Médias seguidas pela mesma letra, na coluna, não diferem entre si pelo teste de Tukey, a 5\%; $\mathrm{PC}=$ primeira contagem do teste de germinação; IVG = índice de velocidade de germinação; $\mathrm{CP}=$ comprimento de plântulas; $\mathrm{PMF}=$ peso da matéria fresca; $\mathrm{PMS}=$ peso da matéria seca; $\mathrm{EA}=$ envelhecimento acelerado; $\mathrm{CE}=$ condutividade elétrica $\left(\mu \mathrm{sm}^{-1} \mathrm{~g}^{-1}\right)$.

Segundo Pinã-Rodrigues (1984), o teste de envelhecimento acelerado se mostra muito promissor em sementes florestais. Para a espécie Parapiptadenia rigida, o período de 48 horas foi suficiente para detectar diferenças significativas na percentagem de germinação (DELGADO e FIGLIOLA, 2003).

Nogueira et al. (2001), em estudo com Anadenanthera colubrina Vell. Bresan, observaram que o envelhecimento acelerado provocou a perda da viabilidade e um declínio na velocidade de germinação das sementes estudadas.

O teste de condutividade elétrica realizado com sementes de cedro, confirmou diferenças entre os locais de coleta e entre as sementes. Assim, foi possível diferenciar os lotes mais vigorosos, e as sementes coletadas no Paraná apresentaram-se, novamente, como as de menor vigor e maior condutividade elétrica. Em estudo com a mesma espécie Borges et al., 1990, usando o teste de condutividade elétrica, observaram que este foi eficiente para detectar a qualidade fisiológica das sementes dessa espécie. Em sementes de Dalbergia nigra, (MARQUES et al., 2002), com o uso do teste de condutividade elétrica, foram distinguidos os lotes, apresentando alta correlação com o teste de germinação, em condições de laboratório e de viveiro.

Os dados referentes à incidência de fungos associados às sementes de Cedrela fissilis podem ser observados na Tabela 3, na qual se verifica que não ocorreram diferenças significativas sendo que a maior percentagem foi de Trichoderma spp. (19\%) nas sementes coletadas no Paraná.

As sementes coletadas em Santa Catarina apresentaram contaminação por Trichoderma spp. e Aspergillus spp. A maior incidência de fungos associados às sementes foi encontrada nas sementes coletadas no Rio Grande do Sul, que apresentou 8,8\% de contaminação por Penicillium spp., 7,9\% por Trichoderma spp. e 5,9\% por Chaetomium spp., sendo que estes fungos não influenciaram a germinação, pois a maior percentagem foi obtida nas sementes coletadas no Rio Grande do Sul. Nunes et al. (2005), observando a qualidade sanitária de cedro, verificaram uma grande incidência de Fusarium spp., que influenciou na percentagem de plântulas normais. Martins Netto e Faiad (1995), no estudo da viabilidade e sanidade de sementes de espécies florestais, concluíram que tais espécies são portadoras de grande variedade fúngica, por isso torna-se importante conhecer a sanidade das sementes para auxiliar na execução de testes de germinação em laboratório e na formação de mudas em viveiro. 
TABELA 3: Incidência de fungos associados às sementes de Cedrela fissilis, coletadas no Rio Grande do Sul, Santa Catarina e Paraná.

TABLE 3: Incidence of fungi associated to the Cedrela fissilis seeds, collected in Rio Grande do Sul, Santa Catarina and Paraná.

\begin{tabular}{l|c|c|c}
\hline Locais & Trichoderma spp. & Penicillium sp. & Aspergillus spp. \\
\hline RS & $7,9 \mathrm{a}$ & $8,8 \mathrm{a}$ & $0,0 \mathrm{~b}$ \\
SC & $13,9 \mathrm{a}$ & $0,0 \mathrm{~b}$ & $2,9 \mathrm{a}$ \\
PR & $19,0 \mathrm{a}$ & $0,0 \mathrm{~b}$ & $0,0 \mathrm{~b}$ \\
\hline CV (\%) & 4,2 & 2,4 & 1,0 \\
\hline DMS (\%) & 0,87 & 0,48 & 0,22
\end{tabular}

Em que: Médias seguidas pela mesma letra, na coluna, não diferem entre si pelo teste de Tukey, a 5\%.

As sementes coletadas no Paraná, que apresentaram baixo vigor, de acordo com os teste realizados, apresentaram somente contaminação por Trichoderma spp., e esse fungo causou interferência na germinação. $\mathrm{O}$ fato de essas sementes apresentarem um baixo vigor pode estar relacionado à maturidade fisiológica. Popiginis (1985) descreve que a diminuição da qualidade de sementes, a partindo da maturidade físiológica, pode ocorrer por causa da incidência de patógenos associados á fatores ambientais, durante a fase de desenvolvimento das sementes e no período de armazenamento.

O uso de sementes de alta qualidade é de grande importância para a instalação e produção de uma cultura, e a qualidade das mudas influencia diretamente no estabelecimento de povoamentos florestais, obtendo-se sucesso ou não em programas de florestamento e reflorestamento. Com isso, a produção, no viveiro, assume grande importância (PIÑA-RODRIGUES, 1988).

$\mathrm{Na}$ Tabela 4, são apresentados os resultados obtidos em casa de vegetação com as sementes de Cedrela fissilis coletadas nos diferentes locais. Os resultados da avaliação da qualidade das mudas mostram que as sementes coletadas no Rio Grande do Sul apresentaram as maiores médias, observadas pels variáveis analisadas, demonstrando assim um maior vigor dessas sementes, o que se reflete nos parâmetros de qualidade de mudas.

As sementes coletadas no Paraná apresentaram uma menor percentagem de emergência de plantas no viveiro (33\%). O uso de sementes de baixa qualidade influencia na formação de mudas de espécies florestais, prejudicando o estabelecimento de povoamentos.

TABELA 4: Avaliação da qualidade de mudas de Cedrela fissilis, obtidas de sementes coletadas no Rio Grande do Sul, Santa Catarina e Paraná

TABLE 4: Evaluation of the quality of Cedrela fissilis seedlings from seeds collected in Rio Grande do Sul, Santa Catarina and Paraná.

\begin{tabular}{l|c|c|c|c|c|c}
\hline \multirow{2}{*}{ Locais } & \multicolumn{7}{c}{ Características } \\
\cline { 2 - 7 } & EP $(\%)$ & AT $(\mathrm{cm})$ & CR $(\mathrm{cm})$ & DC $(\mathrm{cm})$ & PF $(\mathrm{g})$ & PS $(\mathrm{g})$ \\
\hline RS & $71 \mathrm{a}$ & $19 \mathrm{a}$ & $9,1 \mathrm{a}$ & $2,1 \mathrm{a}$ & $8,6 \mathrm{a}$ & $2,7 \mathrm{a}$ \\
SC & $62 \mathrm{~b}$ & $14 \mathrm{~b}$ & $8,1 \mathrm{a}$ & $1,7 \mathrm{ab}$ & $3,2 \mathrm{c}$ & $1,4 \mathrm{~b}$ \\
PR & $33 \mathrm{c}$ & $11 \mathrm{~b}$ & $6,2 \mathrm{~b}$ & $1,5 \mathrm{~b}$ & $4,8 \mathrm{~b}$ & $1,7 \mathrm{~b}$ \\
\hline CV (\%) & 1,0 & 15,0 & 12,0 & 12,0 & 7,0 & 10,0 \\
\hline D.M.S. & 0,26 & 4,58 & 4,09 & 0,43 & 0,77 & 0,48 \\
\hline
\end{tabular}

Em que: Médias seguidas pela mesma letra, na coluna, não diferem entre si pelo teste de Tukey, a 5\%; $\mathrm{EP}=$ emergência de plântulas; $\mathrm{AT}=$ altura total de mudas; $\mathrm{CR}=$ comprimento das raízes; $\mathrm{DC}=$ diâmetro do colo; $\mathrm{PF}=$ peso fresco; $\mathrm{PS}=$ peso seco.

A altura total de mudas foi maior para as mudas procedentes de sementes coletadas no RS, já o comprimento de raízes não apresentou diferença significativa entre as procedentes de Santa Catarina e Rio Grande do Sul. Na avaliação do diâmetro do colo, peso de matéria fresca e peso de matéria seca, os maiores valores foram encontrados para as sementes procedentes do RS.

$\mathrm{Na}$ avaliação de mudas de cedro que apresentavam sintomas de doenças, identificou-se Cylindrocladium spp. e Alternaria sp., fungos causadores de tombamento, presentes nas mudas produzidas partindo de sementes do Rio Grande do Sul. As sementes atacadas no campo e nas operações subseqüentes 
de colheita, secagem e beneficiamento, afetam a sua qualidade, reduzem a sua capacidade germinativa, bem como causam o tombamento de plântulas recém-emergidas (CARNEIRO,1986).

Na Tabela 5, verifica-se que houve correlação negativa com as variáveis SMV e G, para as sementes coletadas no Rio Grande do Sul e Santa Catarina. Este fato ocorreu devido o apodrecimento de sementes na semeadura em viveiro e está associado à presença de fungos, os quais interferem na germinação. Assim, quanto maior o número de sementes mortas, menor será a percentagem de germinação. Na correlação das mesmas variáveis para as sementes procedentes do Paraná, essa tendência não se repetiu.

Para emergência de plantas no viveiro, observou-se correlação positiva com os testes de laboratório, sendo os maiores valores observados entre EPV x CP $(r=0,92)$ e EPV x PS $(r=0,96)$. As sementes avaliadas procedentes do Paraná também apresentaram valores elevados do coeficiente de correlação entre as variáveis de laboratório e viveiro, sendo que os valores positivos observados para G x SMV $(r=0,68)$ e EPV x EA $(r=0,98)$, correlações negativas para EPV x CP $(r=-0,93)$ e EPV x PS $(r=-0,98)$. Em estudo com jacarandá-da-Bahia, Marques et al. (2002) observaram alta correlação entre os resultados obtidos em laboratório e viveiro.

Os resultados obtidos nos diferentes lotes coletados no Rio Grande do Sul, Santa Catarina e Paraná evidenciam a boa associação entre os resultados obtidos em condições de laboratório e em viveiro para a espécie Cedrela fissilis.

TABELA 5: Coeficientes de correlação simples (r) entre os dados obtidos nos testes em laboratório e produção de mudas em viveiro, para avaliação da qualidade fisiológica de sementes de Cedrela fissilis coletadas no Rio Grande do Sul, Santa Catarina e Paraná.

TABLE 5: Coefficents of simple correlation ( $r$ ) between the data obtained in the laboratory tests and production of seedlings, for evaluation of the physiological quality of seeds of Cedrela fissilis collected in the Rio Grande do Sul, Santa Catarina and Paraná.

\begin{tabular}{l|ccccccccc}
\hline Variáveis & SMV & PMVM & IVG & CP & PS & EA & CE \\
\hline RS G (\%) & $-0,99^{*}$ & $0,99^{*}$ & - & - & - & - & - \\
EPV (\%) & - & - & $0,97^{*}$ & $0,91^{*}$ & $0,76^{*}$ & NS & $0,91^{*}$ \\
SC G (\%) & $-0,75^{*}$ & $0,98^{*}$ & - & - & - & - & - \\
EPV (\%) & - & - & $0,50^{*}$ & $0,92^{*}$ & $0,96^{*}$ & $-0,45^{*}$ & $-0,35^{*}$ \\
PR G (\%) & $0,68^{*}$ & $0,29^{*}$ & - & - & - & - & - \\
EPV (\%) & - & - & NS & $-0,93^{* *}$ & $-0,98$ & $-0,98$ & $0,33^{* *}$ \\
\hline
\end{tabular}

Em que: $*$ = significativo a $5 \%$ de probabilidade; $* *=$ significativo a $1 \%$ de probabilidade; $n$ s $=$ não-significativo; $\mathrm{G}=$ Germinação; EPV = emergência de plantas no viveiro; SMV = sementes mortas no viveiro; PMVM = peso da matéria verde de mudas; IVG = índice de velocidade de germinação; $\mathrm{CP}=$ comprimento de plântulas; $\mathrm{OS}=$ peso seco de plântulas; $\mathrm{EA}=$ envelhecimento acelerado; $\mathrm{CE}=$ condutividade elétrica.

Nas sementes pertencentes ao lote do Rio Grande do Sul (Tabela 6), Penicillium spp. apresentou coeficiente de correlação negativa com as variáveis EPV e CR e coeficiente positivo com PMS. Isso indica que esse fungo causa problemas, como o apodrecimento de sementes, sendo que as sementes nem chegam a germinar, ocasionando uma redução na população de mudas, mas não interferindo na qualidade destas. Aspergillus spp., fungo de armazenamento que também causa apodrecimento de sementes, foi encontrado nas sementes coletadas em Santa Catarina e apresentou coeficiente de correlação negativo com as variáveis $\mathrm{G}(\mathrm{r}=-0,99)$, EPV $(\mathrm{r}=-0,86)$ e CTM $(\mathrm{r}=-0,86)$. Espécies de Aspergillus dos grupos Niger e Flavus têm causado decréscimo de germinação (Menten e Bueno, 1987) e, assim como o Penicillium spp., têm promovido lesões nas plântulas, causando um menor desenvolvimento. 
TABELA 6: Coeficientes de correlação simples (r) entre os diferentes testes e incidência de fungos em sementes de Cedrela fissilis coletadas nos diferentes Estados da região Sul.

TABLE 6: Coefficients of simple correlation (r) between the different tests and incidence of fungi in Cedrela fissilis seeds collected in the different States of the South region.

\begin{tabular}{l|c|c|c|c|c|c|c}
\hline $\begin{array}{l}\text { Fungo } \\
\text { s }\end{array}$ & UF & G & EPV & CTM & CR & DC & PMS \\
\hline Penicillium spp. & RS & $0,50^{*}$ & $-0,99^{*}$ & $1,0^{*}$ & $-1,0^{* *}$ & $-0,50^{*}$ & $1,0^{* *}$ \\
Aspergillus spp. & SC & $-0,99^{*}$ & $-0,86$ & $-0,86^{*}$ & $-0,50^{*}$ & $1,0^{* *}$ & $0,30^{*}$ \\
\hline
\end{tabular}

Em que: $*=$ significativo a $5 \%$ de probabilidade; $* *=$ significativo a $1 \%$ de probabilidade; $\mathrm{n}=$ não-significativo; $\mathrm{G}=$ germinação; $\mathrm{EPV}=$ emergência de plantas no viveiro; $\mathrm{CTM}=$ comprimento total de mudas; $\mathrm{CR}=$ comprimento de raízes; $\mathrm{DC}=$ diâmetro de colo; $\mathrm{PMS}$ = peso da matéria seca.

Os gêneros Penicillium e Aspergillus têm a capacidade de reduzir o poder germinativo da semente e causar a morte do embrião. Nos graus de umidade mais baixos das sementes, próximos ao limite mínimo para o crescimento dos fungos, o ataque é lento. Todavia, à medida que o grau de umidade da semente se eleva, torna-se mais rápida a perda de germinação, em virtude do rápido crescimento do fungo (ANGELINI, 1986).

\section{CONCLUSÕES}

Os testes realizados permitiram classificar as procedências das sementes do cedro em diferentes níveis de vigor.

Os testes de primeira contagem, índice de velocidade de germinação, envelhecimento acelerado e condutividade elétrica mostraram que as sementes procedentes do Rio grande do Sul e Santa Catarina apresentaram melhor qualidade.

A presença de patógenos como Penicillium spp. e Aspergillus spp. influenciam na produção final de mudas em conseqüência das perdas pelo apodrecimento de sementes.

\section{REFERÊNCIAS BIBLIOGRÁFICAS}

ANGELINI, A. C. Estudo sobre controle de qualidade durante o armazenamento de sementes embaladas. Campinas: Fundação Cargil, 1986. 51 p.

BORGES, E. E. L.; CASTRO, J. L. D. ; BORGES, R. C. G. Avaliação fisiológica de sementes de Cedro submetidas ao envelhecimento precoce. Revista Brasileira de Sementes, Brasília, v. 12, n. 1, p. 56-62, 1990.

BRASIL. Ministério da Agricultura e da Reforma Agrária. Regras para análise de sementes. Brasília: SNDA/DNDV/CLAV, 1992. $365 \mathrm{p}$.

CARNEIRO, J. S. Microflora associada às essências florestais. Fitopatologia Brasileira, Brasília, v. 11, n. 3, p. 557566, 1986.

CARNEIRO, J. S. Qualidade Sanitária de Sementes de Espécies Florestais em Paraopeba, MG. Fitopatologia Brasileira, Brasília, v. 15, p 75-76, 1990.

CHEROBINI. E. ; MUNIZ. M.F.B.; PIVETTA, G. Qualidade fisiológica e sanitária de sementes de Sesbania virgata. In: CONGRESSO BRASILEIRO DE SEMENTES, 13; 2005, Foz do Iguaçu. Anais...Pelotas:Informativo Abrates, v. 12 , n. 2. p. 256.

DAN, E. L.; MELLO, V. D. C.; WENTZEL, C. T. et al. Transferência de matéria seca como método de avaliação de vigor de sementes de soja. Revista Brasileira de Sementes, Brasília, v. 9, n. 3, p. 45-55, 1987.

DELGADO, L. F; FIGLIOLIA, L. F. Avaliação do vigor de angico vermelho. In: CONGRESSO BRASILEIRO DE SEMENTES, 12; 2003, Gramado. Anais... Brasília: Informativo Abrates, v. 11, n. 2, 2003. p. 355.

FIGLIOLIA, M. B.; OLIVEIRA, E. C.; PIÑA-RODRIGUES, F. C. M. Análise de Sementes. In: AGUIAR, I.B.; PIÑA-RODRIGUES, F.; FIGLIOLA, M.B. (Org.) Sementes florestais tropicais. Brasília: ABRATES, 1993. 350 p.

FRANÇA NETTO, J. B.; PEREIRA, L. A. G.; COSTA, N. P. Metodologia do teste de tetrazólio em sementes de soja. Londrina: EMBRAPA, 1986. 35p.

KRZYZANOWSKI, F. C.; VIEIRA, R. D.; FRANÇA NETTO, J. B. Vigor de sementes: conceitos e testes. Londrina: ABRATES, 1999. $218 \mathrm{p}$.

LORENZI, H. Árvores brasileiras : manual de identificação e cultivo de plantas arbóreas nativas do Brasil. 4.ed. Nova 
Odessa : Plantarum, 1992, v. 2. 352 p.

MARCOS FILHO, J. Teste de envelhecimento acelerado. In.. VIEIRA, R. D.; CARVALHO, N. M. (Eds.). Teste de vigor em sementes. Jaboticabal: FUNEP, 1994. p. 133-149.

MARCOS FILHO, J.; CÍCERO, S. M.; SILVA, W. R. et al. Avaliação da qualidade fisiológica das sementes. Piracicaba: FEALQ, 1987. 230p.

MARQUES, M. A; PAUlA, R. C; RODRIGUES, T. J. D. Adequação do teste de Condutividade Elétrica para a determinação da qualidade de três lotes de sementes de Jacarandá-da-Bahia (Dalbergia nigra Fr. Allen). In: CONGRESSO BRASILEIRO DE SEMENTES, 11; 2002, Curitiba. Anais... Brasília: Informativo Abrates, v. 10, n. 2 , 2002. p. 282.

MARTINS NETTO, D. M.; FAIAD, M. G. R. Viabilidade de sementes de espécies florestais. Revista Brasileira de Sementes, Brasília, v. 17, n. 1, p. 75-80,1995.

MENTEN, J. O. M.; BUENO, J. T. Transmissão de patógenos pelas sementes. In: SOAVE, J.; WENTZEL, M. M. V. S. (Eds.). Patologia de sementes. Campinas: Fundação Cargill, 1987. p. 164 -189.

NAKAGAWA, J. Testes de vigor baseados na avaliação das plântulas. In: VIEIRA, R. D.; CARVALHO, N. M. (Eds.). Testes de vigor. Jaboticabal: FUNEP, 1999. p. 49-85.

NAKAGAWA, J. Testes de vigor baseados na avaliação das plântulas. In: KRZYZANOWSKI, F. C.; VIEIRA, R. D.; FRANÇA NETTO, J. B. (Eds.). Vigor de sementes : conceitos e testes. Londrina : ABRATES, 1999. cap. 2. p.1-21.

NOGUEIRA, A. L; GARCIA, L. C; ABREU, A. C. D. Comportamento de sementes de Anadenanthera colubrina (Vell.) Brenan., Mimosaceae submetidas ao envelhecimento acelerado. In: CONGRESSO BRASILEIRO DE SEMENTES, 2001, Curitiba. Anais... Curitiba: ABRATES, 2001. p. 261.

NUNES, G. H. S; GOIS, F. C.; GRANGEIRO, L. C. Superação de dormência de sementes de juca (Caesalpinea ferrea MART. ESC. TUL). In: CONGRESSO BRASILEIRO DE SEMENTES, 15., 2005, Foz do Iguaçu. Anais... Foz do Iguaçu: ABRATES, 2005. 1 CD-ROM.

PIÑA-RODRIGUES, F. C. M. Perspectivas da utilização do teste de envelhecimento precoce em sementes de essências florestais. In: SIMPÓSIO INTERNACIONAL: MÉTODOS DE PRODUÇÃO E CONTROLE DE QUALIDADE DE SEMENTES E MUDAS FLORESTAIS, 1.,1984, Curitiba. Anais.... Curitiba: UFPR/IUFRO, 1984. p. 291-313.

PIÑA-RODRIGUES, F. C. M. Manual de análise de sementes florestais. Campinas: Fundação Cargill, 1988. 99 p.

PIVETTA, C. U. P., FILHO, S. F. D., PAULA, C. R. Efeito do envelhecimento Acelerado sobre o comportamento germinativo de sementes de Coração-de-negro. In: CONGRESSO BRASILEIRO DE SEMENTES, 11., 2001, Curitiba. Anais... Curitiba: Informativo Abrates, v.10, n.2, 2001. p. 282.

POPINIGIS, F. Fisiologia da semente. Brasília: Ministério da Agricultura. AGIPLAN, 1977. 289 p.

REITZ, R.; KLEIN, R. M.; REIS, A. et al. Projeto Madeira do Rio Grande do Sul. Itajaí: Superintendência do Desenvolvimento da Região Sul - SUDESUL; Governo do Estado de Santa Catarina : Herbário "Barbosa Rodrigues", 1978. 525p.

SANTOS et al. Fungos associados a espécies arbóreas da Mata Atlântica. Colombo: EMBRAPA-CNPF, 2001. p.51-60 (Boletim de Pesquisa, 42).

YORINORI, J. T. Doenças da soja causadas por fungos. Informe Agropecuário, Belo Horizonte, v. 8, n. 94, p. 40-46, 1982.

VIEIRA, R.D.; KRZYZANOWSKI, F.C. Teste de condutividade elétrica. In: KRZYZANOWSKI, F.C. ; VIEIRA, R.D.; FRANÇA NETO, J.B. (Eds.). Vigor de sementes: conceitos e testes. Londrina: ABRATES, 1999. p. 2-26.

ZONTA, E. P.; MACHADO, A. A. Sistema de análise estatística para microcomputadores - SANEST. Pelotas: UFPEL, 1984. Registro SEI n. 066060-0, Categoria AO. 